\title{
Mars core structure-concise review and anticipated insights from InSight
}

\author{
George Helffrich (D)
}

\begin{abstract}
This review summarizes the knowledge of Mars' interior structure, its inferred composition, and the anticipated seismological properties arising from its composition with particular focus on Mars' core. The emphasis on the core stems from the unusual morphology of the liquidus diagram of iron at moderate pressures when enriched in sulfur. From a fairly detailed liquidus diagram constructed from experimental studies, I identify a set of processes that could act within Mars' core: an iron "snow" from the core-mantle boundary's surface and a Fe $\mathrm{F}_{3-x} \mathrm{~S}_{2}$ "ground fog" forming at the base of the core. Depending on temperature and bulk sulfur composition, these could form an inner core or could stratify the outer core by enriching it in sulfur, or both. Core stratification could be one explanation for the extinction of Mars' magnetic field early in the planet's history, and I demonstrate the feasibility of this mechanism. The crystallization processes in the core could be observable in the seismic data that the future Mars geophysical mission, InSight, is planned to provide. The core size, the presence of an inner core, and the wavespeed profile of the outer core, whose radial derivative provides a proxy for changes in composition, are key observables to seek.
\end{abstract}

Keywords: Mars, InSight, Dynamo, Core, Fe-FeS phase relations, Stratification

\section{Introduction}

The Earth's density distribution is known principally through the eigenfrequencies of its whole-body oscillations excited by large earthquakes (Dziewonski and Anderson 1981; Masters and Gubbins 2003). The interior structure of Mars is not as well known as the Earth due to the lack of this type of seismic information. This was not for lack of trying, however. The Viking Lander instrument package included a seismometer, but it was not deployed on the ground. Its placement on the lander deck led to high noise levels due to wind-induced motion of the probe and thus low signal-to-noise levels for seismic signals (Lorenz and Nakamura 2013). Only one potential earthquake was recorded (by the Viking 2 lander; the Viking 1 instrument failed), limiting the seismicity to levels significantly lower than the Earth. The putative earthquake was shallow and located about $100 \mathrm{~km}$ from the lander (Anderson et al. 1977). The small event was not energetic enough to set the body of the planet vibrating; hence, no inferences on internal structure were possible.

Correspondence: george@elsi.jp

Earth-Life Science Institute, Tokyo Institute of Technology, 2-12-1-IE-1

Ookayama, Meguro-ku, Tokyo 152-8550, Japan
Consequently, physical parameters provided by astronomical and orbital measurements yield the only constraints on Mars' internal structure. According to Rivoldini et al. (2011), they are the bulk planet density $3934.97 \pm 1.2 \mathrm{~kg} \mathrm{~m}^{-3}$, the mean moment of inertia $I /\left(M r^{2}\right) 0.3645 \pm 0.0005$, and the elastic tidal Love number $k_{2} 0.159 \pm 0.009$. The $k_{2}$ value itself indicates that the core is at least partially liquid and in a range of 1520 $1840 \mathrm{~km}$ (Yoder et al. 2003). Using these further properties to constrain internal structure requires a mineralogical and thermal model of the planet; hence, the estimates in Table 1 are model dependent.

Mars' core (radius 1600-1810 km according to Konopliv et al. (2006)) is about half the radius of Earth's (3480 km according to PREM (Dziewonski and Anderson $1981)$ ), and the planetary radius (3389.5 $\mathrm{km}$ according to Seidelmann et al. (2002)) is also about half of Earth's (6371 $\mathrm{km}$ again according to PREM). Hence, the interior structure of Mars is roughly a half-sized scale model of the Earth (Fig. 1), and the core occupies an eighth of the planetary volume. Mars' core mass is about 0.24 of the planetary mass (Table 1), and Earth's core mass fraction is 0.32 (Stacey 1992). The pressure at the center of the 
Table 1 Mars internal properties

\begin{tabular}{lllll}
\hline Property & Model & Value & \multicolumn{2}{c}{$95 \%$ conf. range } \\
\hline Core radius (km) & Median (cold) & 1810 & 1701 & 1900 \\
& Median (hot) & 1784 & 1673 & 1879 \\
& Average & 1797 & & \\
Core mass fraction & Median (cold) & 0.2404 & 0.2095 & 0.2683 \\
& Median (hot) & 0.2327 & 0.2171 & 0.2474 \\
Core-mantle boundary P (GPa) & Median (cold) & 19.0 & 17.8 & 20.4 \\
& Median (hot) & 19.4 & 18.1 & 20.0 \\
& Average & 19.2 & & \\
\hline
\end{tabular}

Source: Rivoldini et al. (2011)

planet 37-38 GPa (Rivoldini et al. 2011) is much lower than Earth's central pressure of $364 \mathrm{GPa}$ (Dziewonski and Anderson 1981). The InSight mission, due for launch in May 2018 (originally March 2016) and to reach Mars in November 2018, is a lander designed as a geophysical observatory (Banerdt et al. 2013). Its instrument package includes a heat flow sensor, a seismometer, a magnetometer, wind and temperature sensors, and a radio transponder for lander range tracking that will supply geodetic data. Unlike the Viking missions, the seismometer is deployed separately on the surface next to the lander. Some quite basic seismic observations will significantly constrain compositional and structural models of Mars' interior. Here, I will review the key observations and what they will tell us about alternative interior structures. The review is concise, forfeiting a broad topical survey to focus instead on how the seismological information will elucidate core structure. The reviews of InSight mission seismology objectives found in Panning et al. $(2015,2017)$ cover aspects of marsquake location precision and silicate mantle structure.

\section{Review \\ Composition}

The composition of Earth's core, like Mars', is not directly observable. The core's seismic wavespeeds do provide significant constraints on composition due to the velocitydensity systematics discovered by Birch (1952), who showed that there were systematic relations between the density and liquid seismic velocity depending on mean atomic weight. While the density-seismic velocity relation of the Earth's core, as revealed by its seismic wavespeed profile, was close to that experimentally determined for pure iron, it did not coincide. Thus, Birch estimated that there was $\sim 10 \mathrm{wt} \%$ lighter material alloyed with the core's iron, an estimate not much improved after 60 years of further study. Denied this information about Mars' core, the inferences become more tenuous and model dependent,

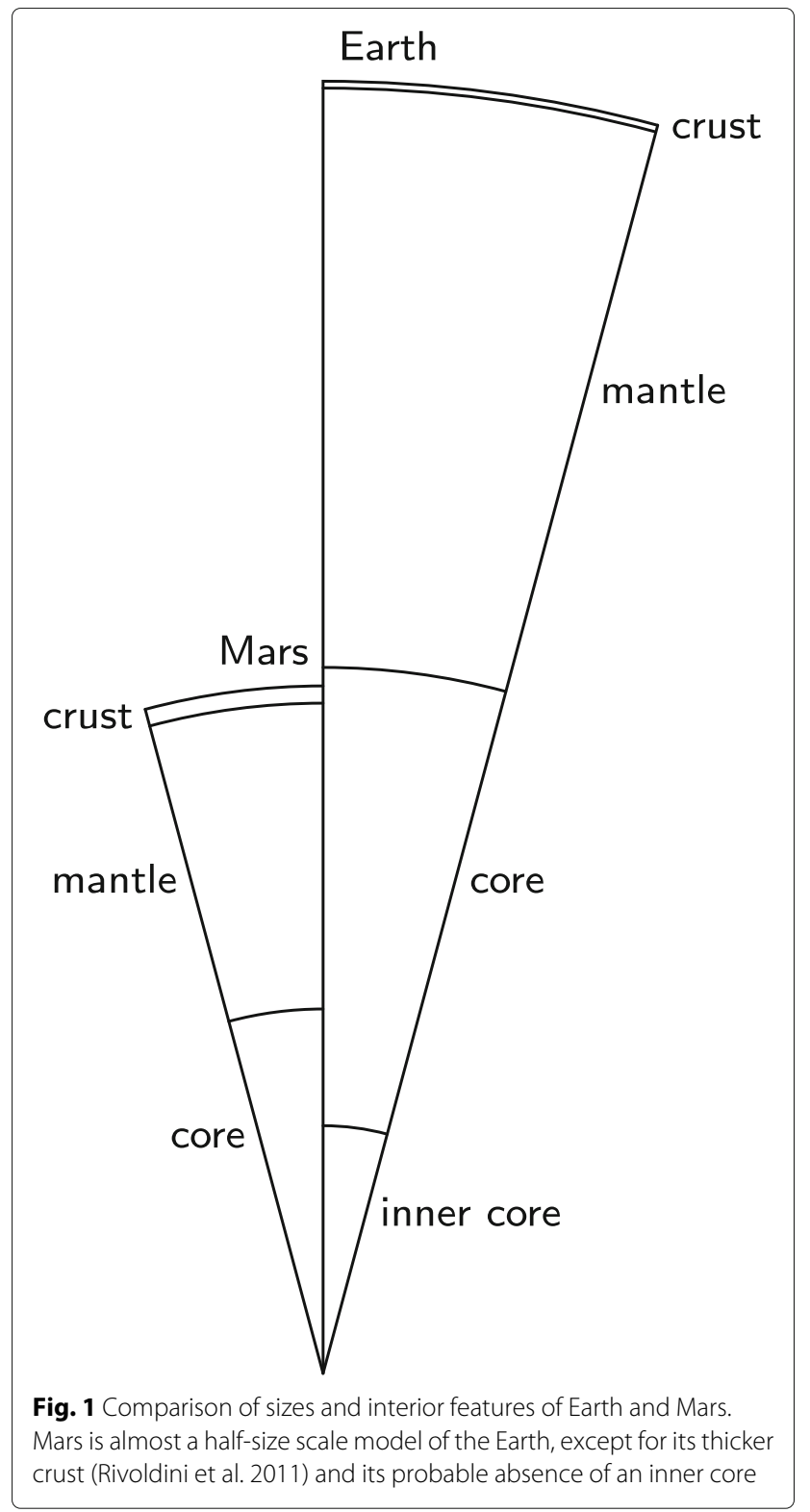

but comparison with Earth suggests the level of detail that will emerge once Mars is studied seismologically.

There are two main sources of compositional information: geochemical/cosmochemical and geophysical. The models underlying the use of the geophysical information provide a range of potential compositions for the core, as shown in Fig. 2. The models start with a bulk composition based on CI chondrites or the composition of SNC meteorites (believed to be Mars crustal fragments excavated by impacts on Mars), a mineralogical model for the composition as a function of pressure and temperature, and then attempt to match planetary mass, radius, and moment of inertia by varying a quasi-adiabatic temperature profile through the planet. Core metal is taken to be Fe-Ni alloy with added light elements $\mathrm{S}, \mathrm{C}, \mathrm{Si}, \mathrm{O}, \mathrm{N}$, and $\mathrm{H}$. 
Rivoldini et al. (2011) models only considered sulfur as an alloying element. This is almost certainly wrong, but Rivoldini et al. (2011) argue for its likelihood, partly on the basis of the antipathy that $\mathrm{S}$ and $\mathrm{Si}$ have in iron (Kilburn and Wood 1997) and the fact that, at low pressure, O solubility in liquid metal is low (Rubie et al. 2004). (Systematic depletions of siderophile elements in the Earth's core, for example, suggest that it harbors significant amounts of $\mathrm{P}$, $\mathrm{Sb}, \mathrm{Se}, \mathrm{Te}, \mathrm{Ag}$, and $\mathrm{Ge}$, in addition to $\mathrm{Ni}$ and $\mathrm{S}$ and the possible, but thermodynamically unlikely, $\mathrm{Si}$ and $\mathrm{O}$ for these conditions (Rubie et al. 2004; Wood et al. 2006). These are in fact the bases for cosmochemical estimates of the Earth's core composition (Allègre et al. 1995; McDonough and Sun 1995)). Martian meteorites themselves suggest a core composition of 11-15 wt\% S (Dreibus and Wänke 1987; Lodders and Fegley 1997). Nevertheless, Rivoldini et al.s (2011) modeling efforts revise this to 15-17 wt\% $\mathrm{S}$ in the core. I consider the range to be, conservatively, 11-17 wt\%. Earlier estimates for Mars' core from various sources yield a range of $14-17 \mathrm{wt} \%$ (and one as low as $10.5 \mathrm{wt} \%$ ), yet all suggest much more than is believed to be in Earth's core: 1.7 wt\% (Dreibus and Palme 1996).

\section{Phase relations}

Figure 3 shows the approximate melting relations in the Fe-FeS system derived from various sources (Fe melting curve (Nguyen and Holmes 2004), Fe-FeS melting relations (Fei et al. 1997; Fei et al. 2000; Morard et al. 2008; Buono and Walker 2015)). For the conditions in Mars' core, the first solids to crystallize are likely to be $\mathrm{Fe}_{3-\mathrm{x}} \mathrm{S}_{2}$ if the composition is relatively rich in sulfur and Fe otherwise. In either case, $\mathrm{Fe}_{3} \mathrm{~S}$ will be the dominant crystalline phase in Mars' inner core after the core entirely solidifies and if it undergoes subsolidus equilibration. A naive reading of the lack of a present-day magnetic field (Acuña et al. 1999 ) is that an inner core is absent, incapable of releasing compositional buoyancy to drive a dynamo. A more complex view attributes the end of Mars' dynamo era to substantial stagnation of the core, leading to an annular dynamo (Takahashi and Matsushima 2006) becoming too thin to sustain activity (Olson and Christensen 2002; Christensen and Aubert 2006). The solids that do crystallize in the core lead to quite different outcomes compared to the Earth due to the difference in core composition. Figure 4 shows the conditions for core crystallization. If core $\mathrm{CMB}$ temperature $T_{\mathrm{CMB}}$ is less than $1300 \mathrm{~K}$, the core will be completely solid. This is ruled out by value of the $k_{2}$ tidal Love number, placing a firm lower bound on $T_{\mathrm{CMB}}$. If $T_{\mathrm{CMB}}>\sim 1550 \mathrm{~K}$, the core will be completely liquid. More interesting phenomena arise when $1300 \leq T_{\mathrm{CMB}} \leq 1500 \mathrm{~K}$. In all cases, Fe will crystallize at the top of the core, forming an iron "snow" (Stewart et al. 2007). Moreover, if $T_{\mathrm{CMB}}<1450 \mathrm{~K}, \mathrm{Fe}_{3-\mathrm{x}} \mathrm{S}_{2}$ will crystallize at the core's center and produce a phenomenon akin

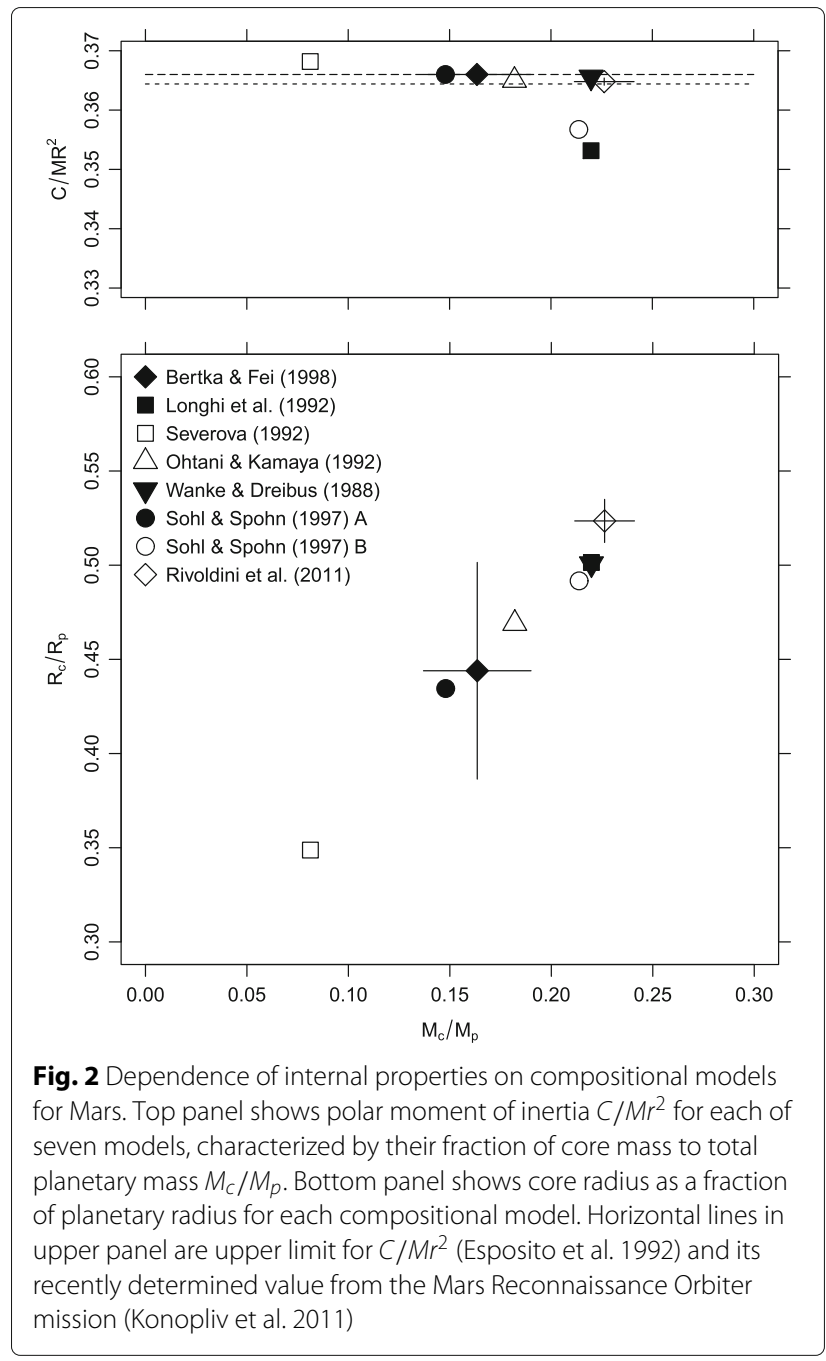

to ground fog on Earth. Unlike the water droplets making up fog, the solid is considerably more S-rich ( 28 wt\% $\mathrm{S}$ compared with the liquid's 14-16 wt\% S) sinking and depleting the remaining liquid in S. If well-mixed, this will effectively foster further Fe crystallization because the remaining liquid will crystallize iron. If not well-mixed, the lowermost core will stratify due to Fe-rich liquid left there by $\mathrm{Fe}_{3-\mathrm{x}} \mathrm{S}_{2}$ crystallization. The inverse will happen near the CMB: denser Fe will snow downwards in the core and leave the outermost liquid richer in S. If convection is not vigorous enough, the stratification could stabilize the core into compositionally distinct layers, in which convection occurs only in the steadily shrinking wellmixed central zone. This might quell dynamo activity and end Mars' magnetic era (Weiss et al. 2002; Williams and Nimmo 2004), like what may be occurring in Ganymede (Rückriemen et al. 2015).

The route to Mars' core stratification may be visualized with the help of Fig. 5. The figure shows the areas 
affected by the crystallization of solids as a function of temperature at the CMB. It is derived from Fig. 3 by fixing a $\mathrm{CMB}$ temperature and following an adiabat with $\gamma=1.4$ (see Fig. 4) down into the core (upward in pressure) and plotting the $\mathrm{S}$ content at the liquidus for the different crystallizing phases $\left(\mathrm{Fe}\right.$ and $\mathrm{Fe}_{3-x} \mathrm{~S}_{2}$ ). For adiabatic temperature profiles initiated there at temperatures cooler than $1575 \mathrm{~K}$, the top of the core will snow iron downwards (Stewart et al. 2007). At CMB temperatures less than $\sim 1420 \mathrm{~K}$, solid $\mathrm{Fe}_{3-\mathrm{x}} \mathrm{S}_{2}$ will simultaneously crystallize at the bottom of the core. The combined effects will enrich the remaining core liquid in $\mathrm{Fe}$, due to crystallization at the center, and to snow Fe downward from above due to the crystallization at the surface. If equilibrium conditions prevail, the snow would descend until it was dissolved back into the remaining liquid and the liquid would adopt an outwardly increasing $\mathrm{S}$ enrichment profile controlled by the Fe solubility along the adiabat. The isotherms of $\mathrm{Fe}_{3-x} \mathrm{~S}_{2}$ crystallization show that the inner core size increases rapidly as the CMB temperature drops: for example, if the bulk $\mathrm{S}$ content is $15 \mathrm{wt} \%$, the inner core will grow from 0 to $500 \mathrm{~km}$ in radius with a CMB temperature change of about $80 \mathrm{~K}$. These phenomena will have

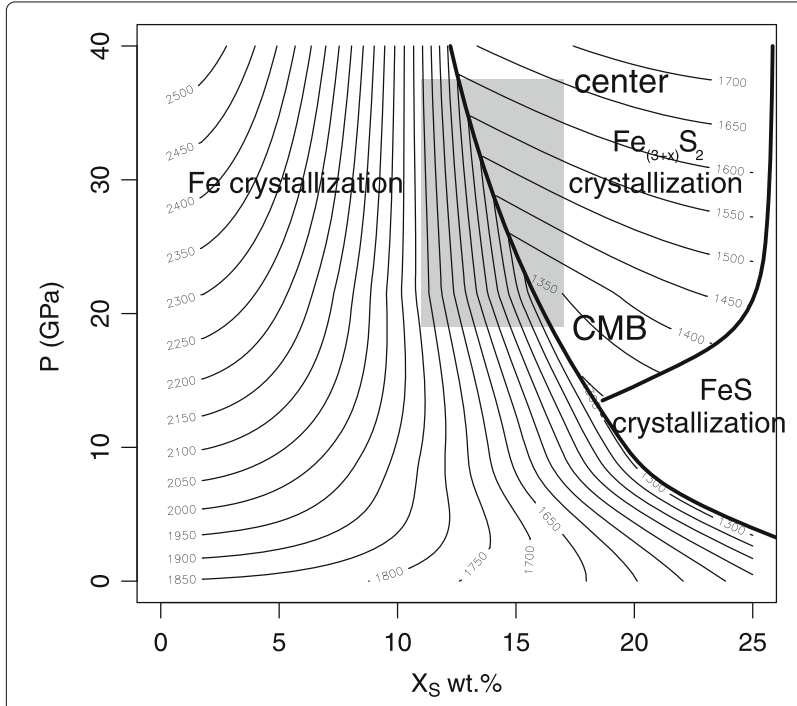

Fig. 3 Melting relations in the Fe-FeS system in the pressure and compositional range suitable for Mars' core. Isotherms show temperature (K) of appearance of first solid in the system depending on the composition and pressure. Thick lines delimit fields of first crystallizing solid: $\mathrm{Fe}, \mathrm{FeS}$, and $\mathrm{Fe}_{3-x} \mathrm{~S}_{2}$ (Fe-FeS eutectic on left and incongruent melting of $\mathrm{Fe}_{3-x} \mathrm{~S}_{2}$ on right). Gray box shows likely pressure and compositional range for core. Intersection of box with isotherms shows that for any crystallization of solids in the inner core, temperatures must be less than $\sim 1650 \mathrm{~K}$. First solids to crystallize will be $\mathrm{Fe}_{3-x} \mathrm{~S}_{2}$ if in $\mathrm{S}$-rich compositions and will be Fe if S-poor. When eutectic reached, crystallizing solids will vary depending on subsolidus phase diagram but will ultimately be $\mathrm{Fe}+\mathrm{Fe}_{3} \mathrm{~S}$ or $\mathrm{Fe}_{3-x} \mathrm{~S}_{2}+\mathrm{Fe}_{3} \mathrm{~S}$ (Fei et al. 2000)

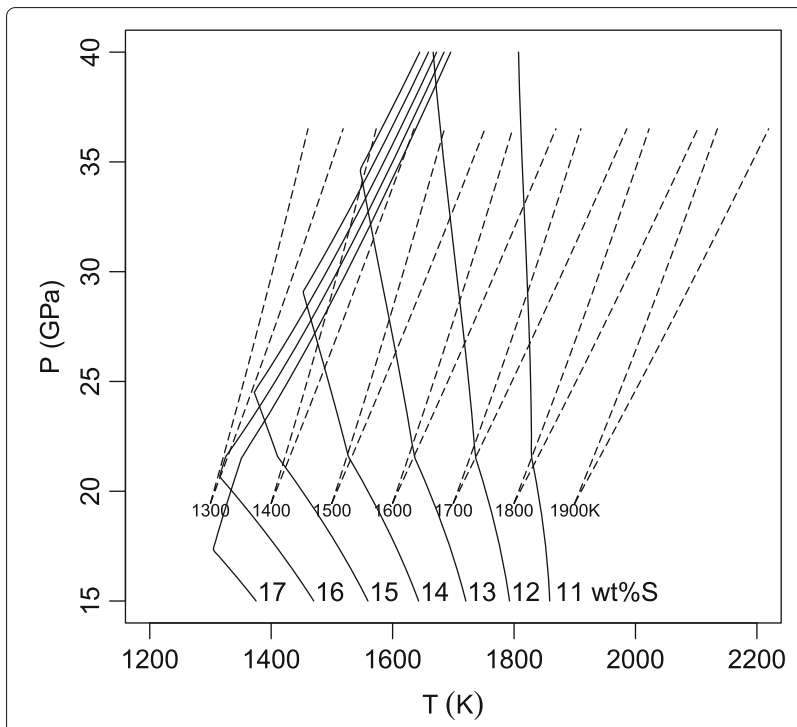

Fig. 4 Liquidus curves for a suite of fixed compositions in Mars' core (solid lines; these are iso-compositional sections through Fig. 3), superimposed with various adiabatic temperature profiles initiated at the core-mantle boundary (dashed lines; ranges shown for $1.2 \leq \gamma \leq 1.6$ for each labeled $T_{\mathrm{CMB}}$ ) and extending through the core. Fe crystallizes where the liquidus curve slope is negative, whereas $\mathrm{Fe}_{3-x} \mathrm{~S}_{2}$ crystallizes if the slope is positive (Fig. 3). For $T_{C M B}<1300 \mathrm{~K}$, the core is solid, whereas if $T_{C M B}>1450 \mathrm{~K}$ it is liquid. At any $T_{C M B}<1850 \mathrm{~K}$, the top of the core crystallizes an Fe 'snow'; if, moreover, $T_{\mathrm{CMB}}<1450 \mathrm{~K}$, the base crystallizes an $\mathrm{Fe}_{3-x} \mathrm{~S}_{2}$ "ground fog." Adiabats calculated using $d \log (T) / d z=\gamma g(r) / V_{p}^{2}(r)$ with $z$ the depth below the CMB using data from Rivoldini et al. (2011)

a detectable effect on the seismological structure of the core, which is the next topic in this review.

\section{Seismology}

For comparison, I focus on two seismological models of Mars' interior developed by Sohl and Spohn (1997) and by Rivoldini et al. (2011). The approaches they took to construct the models were similar, using meteorite-based compositional information to predict the mineral assemblages as a function of radius and hence the radial density profile, refining the internal temperature profiles until a match was achieved to the basic planetological data (radius, moment of inertia and $k_{2}$ Love number). As a side effect of these calculations, the models also provide seismic wavespeed profiles.

Sohl and Spohn (1997) essentially took a single compositional model due to Wänke and Dreibus (1988) and relied on either the chondritic Fe/Si ratio (1.71) to fix the bulk the mantle/core partitioning of iron (and thus the oxidation state of the mantle) or relied on matching the rotational moment of inertia, $C$, to its upper limit of $0.366 \times M r^{2}$ as then known from available data. It was not possible to satisfy both constraints simultaneously, so they provided two solutions, A and B. I 
show here for comparison model A because its philosophy is most similar to those explored by the following alternative.

Rivoldini et al. (2011) used a Bayesean approach to solving the internal structure problem. They used updated astronomical and geodetic data for Mars and a wider suite of composition models advanced by meteoriticists as well as researchers who explored the phase relations in the silicates comprising Mars' mantle and the metal content of its core. Aggregates of solutions were developed that fit the observational data within each compositional model, and assuming temperature profiles through the planet that were "hot" and "cold." The statistics of the aggregate solutions provided confidence levels for each model, one of which is shown in Table 1.

I compare Sohl and Spohn (1997) model A with Rivoldini et al. (2011) "cold" profile in the Dreibus and Wänke (1985) compositional model because these represent similar geotherms and similar bulk compositions. Thus the essential differences are the advance in the state of physical knowledge and the methodology improvement (due to increased computing power) between the modeling efforts. The resulting wavespeed and density profiles

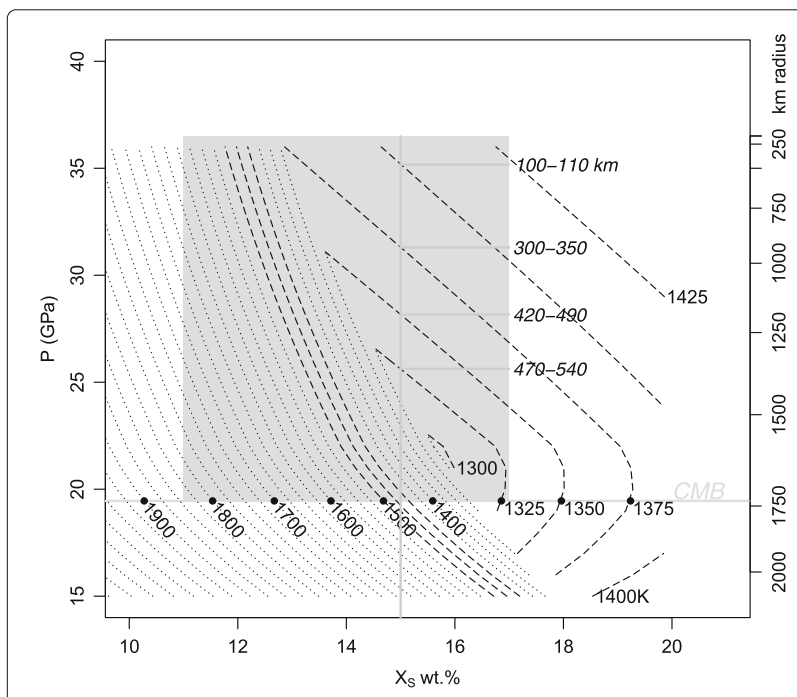

Fig. 5 Crystallization process of Mars' core. Contours show pressure (left scale) and radius (right scale) where crystallization takes place along an adiabat extending from the CMB (horizontal gray line, labeled with $\left.T_{C M B}\right)$. Dotted lines show Fe crystallization conditions, whereas dashed lines show $\mathrm{Fe}_{3-x} \mathrm{~S}_{2}$ crystallization conditions. Gray box shows pressure/radius range of the core, and the anticipated compositional range of the core; range of radii of solid inner core crystallized from the liquid of $15 \mathrm{wt} \% \mathrm{~S}$ (vertical line) indicated by italic labels within the box. The dashed adiabatic temperature contours show that the core will grow rapidly with small changes in CMB temperature. The dotted Fe crystallization contours show that an iron 'snow' will form at the top of the core at temperatures below $\sim 1575 \mathrm{~K}$. The range of inner core radii arises from alternative compositions of the solid core: $\mathrm{Fe}_{3} \mathrm{~S}_{2}$ or $\mathrm{Fe}_{3} \mathrm{~S}$

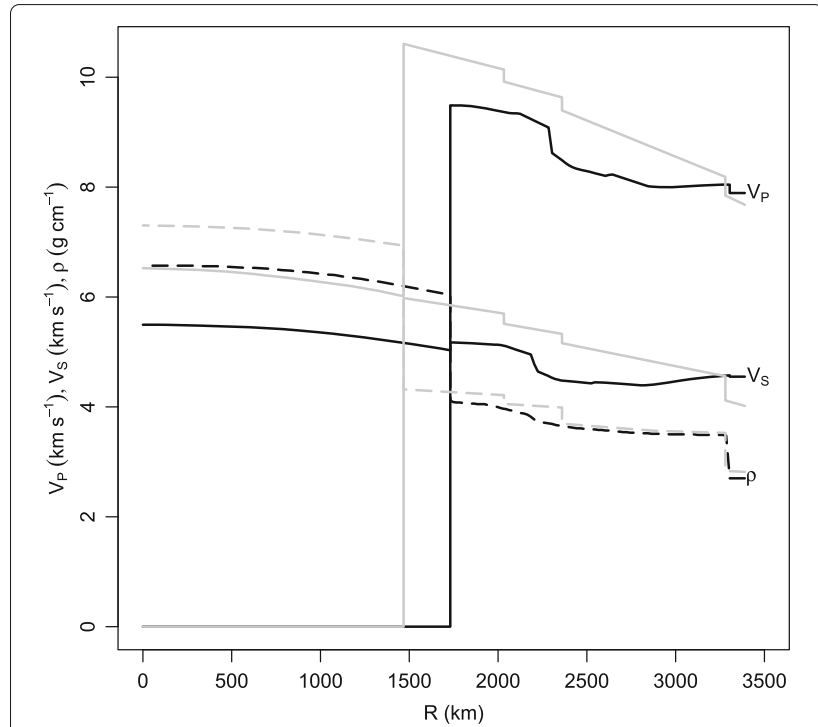

Fig. 6 Radial wavespeed and density profiles of two Mars internal structure models, Rivoldini et al. (2011) (R11DW black) and Sohl and Spohn (1997) (SS97a gray). The most pronounced difference between them is their core size. Other important seismological details are that R11DW's core wavespeed is lower than $V_{S}$ at the base of the mantle, whereas SS97a's is slightly higher

are shown in Fig. 6. The main difference between them is their core size. With a chondritic $\mathrm{Fe} / \mathrm{Si}$ ratio, their model B core $(1667 \mathrm{~km}$; not shown) is larger and similar to Rivoldini et al. (2011) core size, $1731 \mathrm{~km}$. The two models' crust thicknesses are similar, $\sim 100 \mathrm{~km}$. The mantle seismic wavespeed profiles differ because Sohl and Spohn (1997) use a simplified peridotitic mantle model and first-order discontinuities at the transitions between the olivine polymorphs (olivine, wadsleyite, and ringwoodite), whereas Rivoldini et al. (2011) use a more complete mantle model and allow for two-phase regions through the polymorph transition intervals. There is no transition to bridgmanite in either model. Mantle densities are broadly similar. The smaller core of Sohl and Spohn (1997) model requires it to have a higher density to match the planetary mass. Hence, there is less light element in the core, and wavespeeds are correspondingly higher.

To illustrate the first-order information that seismology will yield about Mars' core, I show the travel time curves for selected arrivals of interest to constrain internal structure. Figure 7 shows two diagrams for the Sohl and Spohn (1997) model, with and without an inner core. The model is meant only to be illustrative; the inner core is only a scaled version of Earth's inner core transplanted to Mars, with similarly scaled radius and $V_{P}$ jump; a more realistic model will be examined below. The diagrams show a pronounced difference in travel times. The geometries of the individual curves are key structural information about the interior, as indicated in the figure caption. 

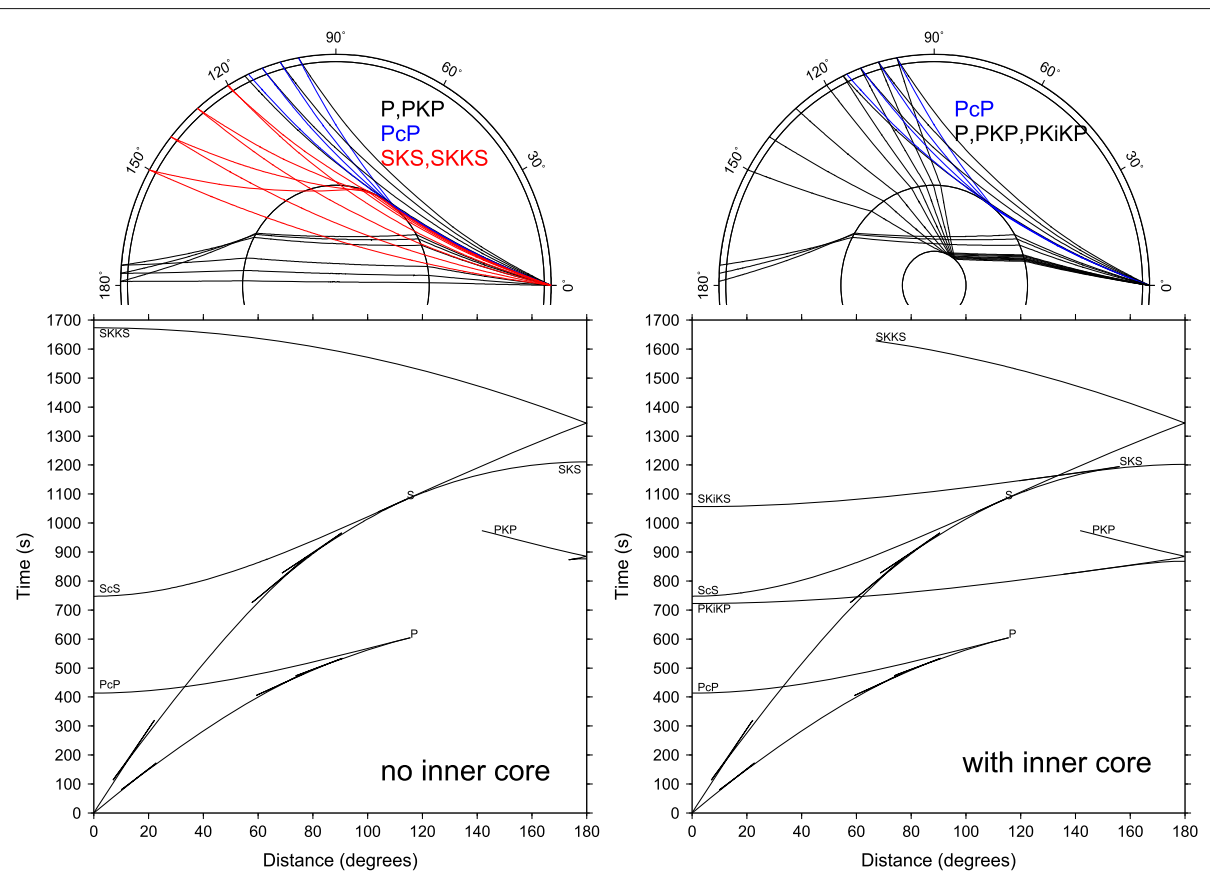

Fig. 7 Ray paths (top) and calculated travel times (bottom) in the Sohl and Spohn (1997) model A, with (right) and without (left) an inner core. The inner core's properties are only scaled version of the Earth's inner core and only meant to be indicative of the change in the travel time curves, and not otherwise physically justified. The horizontal axis is distance from an earthquake source at 0 , measured in degrees of arc around the planet. The lag time until an arrival is seen is the time plotted on the vertical axis. Each type of seismic wave arrival traces a continuous path as a function of distance. Curves with positive slopes travel directly between the source and receiver (along the minor arc, to distances $<180^{\circ}$ ). Curves with negative slopes travel the long way around the sphere (along the major arc to distances $>180^{\circ}$ ). Each wave type is labeled with its name (see the "Appendix" section for nomenclature). The core's low wavespeeds with respect to the mantle cause a P-wave arrival shadow, the gap between P and PKP between $\sim 120-\sim 180^{\circ}$ (top left). The main difference is that the inner core reflection PKiKP (and PKIKP) illuminates the shadow region when an inner core is present (top right). SKS and SKKS illuminate the core, but the ranges of the SKS $\left(>160^{\circ}\right)$ and $\operatorname{SKKS}\left(>300^{\circ}\right)$ arrivals are truncated by the presence of an inner core

A comparison of the travel time curves and their associated ray paths provides further insights as to how different models lead to different travel time curves. Figure 8 compares Sohl and Spohn (1997) model A (SS97a) with Rivoldini et al. (2011) model based on the Dreibus and Wänke (1985) compositional model (R11DW). The first difference between the models is the near-constant $V_{P}$ in the shallow mantle of R11DW. These lead to straight-line ray paths, and a slope for the $\mathrm{P}$ travel time curve that is less curved than the corresponding curve for SS97a. The second difference is that of core size. PcP (a corereflected $\mathrm{P}$-wave) arrives earlier when the core is larger. This constrains the core size, and hence the $\mathrm{Fe} / \mathrm{Si}$ ratio of the planet. The final difference is the travel time curve for SKKS. Due to the lower core $V_{P}$ compared to $V_{S}$ at the base of the mantle, there is a shadow (gap) in the travel time curve for SKS and SKKS. The very small increase at the core-mantle boundary in the SS97a model eliminates the shadow (see Fig. 7) and leads to a "whispering gallery" effect at the top of the core (wave fronts may travel horizontally just under the boundary), illuminating its structure up the the outermost core surface. In contrast, with R11DW, the outermost outer core's structure will be less visible. Owing to SKS' high amplitude (Panning et al. 2017) and polarization in the vertical plane, it should be visible with the InSight instrumentation. This arrival's travel time curve will probably be the main way to determine core structure since the PKP amplitude is considerably lower.

Figure 9 shows the sensitivity limits of various corerelated arrivals given the design criteria of the sensors on the InSight lander. One obvious difference is that of the two models, SS97a leads to more visible core arrivals. This is essentially due to the size of the velocity jump at the CMB: larger velocity jumps lead to stronger reflections (PcP, ScS) at short range, and more efficient propagation into the core (SKS, SKKS) at long range. It appears that short-range $\left(5^{\circ}-15^{\circ}\right) \mathrm{ScS}$ and $\mathrm{ScP}$ observations will give the best information about core size. However, longerrange ScP, ScS $\left(20^{\circ}-75^{\circ}\right)$ and SKS or SKKS $\left(>75^{\circ}\right)$ may also provide valuable constraints on core size. Unfortunately, core arrivals are so weak that they require large earthquakes (in excess of $6.0 \mathrm{M}_{\mathrm{w}}$ ) and low environmental noise for detection. Taylor et al. (2013) estimate from faults 


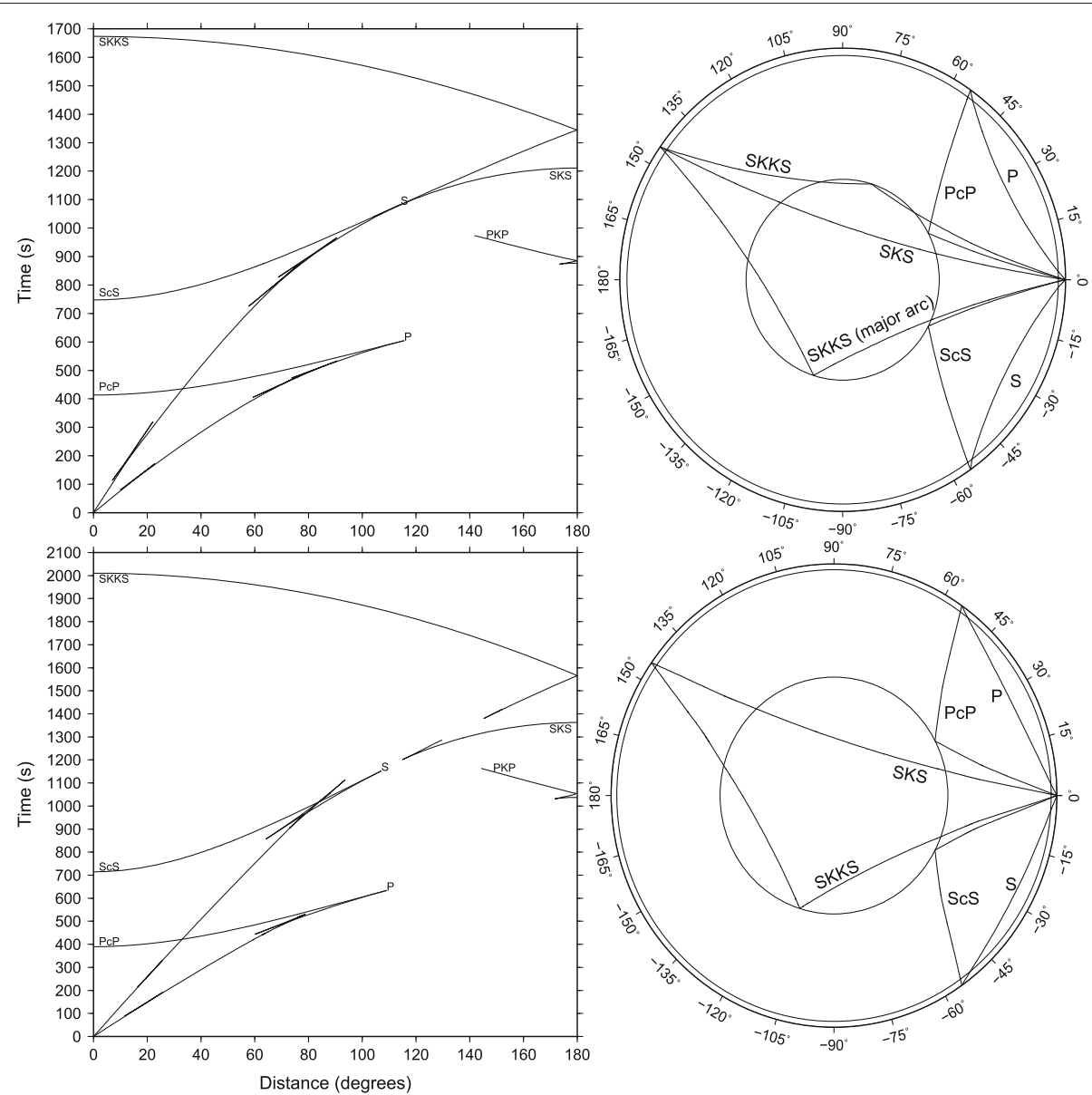

Fig. 8 Travel time curves (left) and ray paths (right) for two different Mars seismic models. (Top panels) Sohl and Spohn (1997) model A (SS97a); (bottom panels) Rivoldini et al. (2011) model based on the Dreibus and Wänke (1985) compositional model (R11DW). The diagram shows how the combination of core sizes and wavespeeds at the top of the outer core relative to $V_{S}$ at the base of the mantle affect the gross form of the seismic wave arrivals. The right panels show rays emanating from a seismic source at $0^{\circ}$ to stations at 55 and $145^{\circ}$. R11DW features a core shadow to SKS and SKKS due to its lower core wavespeeds, one effect of which is that minor arc SKKS disappears at $130^{\circ}$. The core size affects the travel time of the core reflected arrivals PCP and SCS

in Mars' Cerberus Fossae region that $0.2-500$ detectable earthquakes of this size could occur per Earth year, suggesting that optimism is warranted for constraining the core's size. Cerberus Fossae is around $25^{\circ}$ from the InSight landing site on Elysium Planita, putting the marsquake region at a range of relatively high sensitivity for $\mathrm{ScS}$ and ScP core reflections (Fig. 9).

Stratification of the core may result if a favorable combination of temperature and composition prevails (Fig. 5). The temperatures anticipated at the CMB for Rivoldini et al. (2011) models are between $\sim 1700-2100 \mathrm{~K}$, and for Sohl and Spohn (1997) models are $~ 1750$ $1950 \mathrm{~K}$. These are too high for any inner core formation (Fig. 4). However, these models were constructed without including the mineralogy for $\mathrm{Fe}_{3-\mathrm{x}} \mathrm{S}_{2}$ or $\mathrm{Fe}_{3} \mathrm{~S}$ forming the inner core, and the consequences of its crystallization for stratification. (Rivoldini et al. (2011) explored inner core sizes but assumed Fe as the only constituent solid.) Without exploring the resulting core structure's compatibility with the $I /\left(M r^{2}\right)$ and $k_{2}$ constraints (but see the post-hoc justification later), I calculate the seismic signature of a stratified model with an inner core. Some simplifications are in order to avoid burdening the review with excessive details of thermophysical properties and equations of state; a brief summary appears in the "Appendix" section. I use the estimated thermophysical properties of $\mathrm{Fe}_{3} \mathrm{~S}_{2}$ and $\mathrm{Fe}_{3} \mathrm{~S}$ (Saxena and Eriksson 2015) to calculate the density of the solid and compare it with liquid density estimates from previous core models (Rivoldini et al. 2011; Sohl and Spohn 1997). The densities at Mars' center are $7701 \mathrm{~kg} \mathrm{~m}^{-3}$ $\left(\mathrm{Fe}_{3} \mathrm{~S}_{2}\right)$ and and $8330 \mathrm{~kg} \mathrm{~m}^{-3}\left(\mathrm{Fe}_{3} \mathrm{~S}\right)$ are greater than the liquid densities $\left(6600-7300 \mathrm{~kg} \mathrm{~m}^{-3}\right)$, so the crystals would sink. The resulting inner core size depends on 


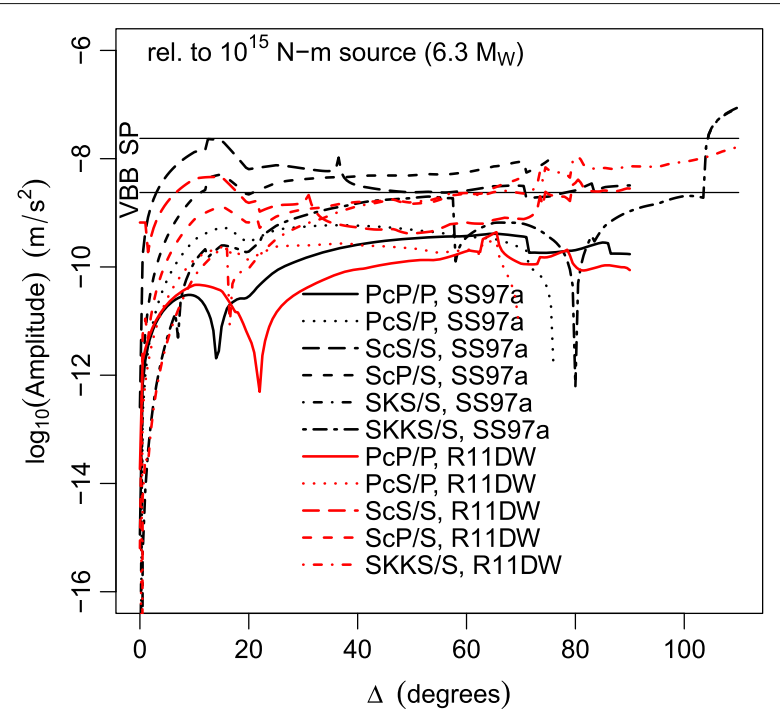

Fig. 9 Detection limits of selected core-related arrivals needed to determine core radius and outer core structure. Various curves show the expected acceleration levels expected for a $10^{15} \mathrm{~N}$-m source recorded at various ranges (in degrees of great circle arc) from the seismometer. The sensitivity levels of the InSight SP and VBB instruments are shown as horizontal lines (Lognonné et al. 2014). For methods used, see the "Appendix" section

whether $\mathrm{Fe}_{3} \mathrm{~S}_{2}$ or $\mathrm{Fe}_{3} \mathrm{~S}$ (or a mixture of both) is the stable high-pressure assemblage at Mars' center. The assemblage itself depends on both the precise phase relations (Fei et al. 2000; Saxena and Eriksson 2015) and the presence of other alloying elements such as Ni (Stewart et al. 2007), so a range of inner core sizes results from a single bulk core composition and CMB temperature (Fig. 5). Rivoldini et al. (2011) models found a range of core radii (of pure $\mathrm{Fe}$ ) of $500 \pm 500$ and $600 \pm 500 \mathrm{~km}$ depending on the CMB temperature, 1700 and $2100 \mathrm{~K}$, respectively. For a core with $15 \mathrm{wt} \% \mathrm{~S}$, the ICB radius may be as large as $500 \mathrm{~km}$ if $\mathrm{Fe}_{3} \mathrm{~S}_{2}$, suggesting that a more sulfur-rich solid in the core is also capable of satisfying the $I /\left(M r^{2}\right)$ and $k_{2}$ constraints.

To show the features resulting from a stratified core, I construct a core structural model that contains an inner core and a sulfur-rich layer at the top of the core from the liquidus relations shown in Fig. 5. The CMB temperature is $1350 \mathrm{~K}$. At a bulk core composition of $15 \mathrm{wt} \%$ sulfur, the inner core size is $490 \mathrm{~km}$. Because crystallization of Fe at this temperature deflects the core liquid's sulfur content to the adiabat, the topmost $200 \mathrm{~km}$ of the core will be stratified. Depletion of sulfur at the base through crystallization of $\mathrm{Fe}_{3} \mathrm{~S}_{2}$ and at the top by $\mathrm{Fe}$ pumping down the adiabat reduces the bulk liquid S content slightly to $14.5 \mathrm{wt} \%$. The liquid part of the core is $1111 \mathrm{~km}$. Figure 10 shows the structure, travel time curves, and ray paths compared with R11DW.
The effect of stratification is the wavespeed and density reduction in the core in the $200 \mathrm{~km}$ nearest to the CMB. Density is affected most strongly: it is reduced by about $1 \%$ relative to the ambient core density. The effect on wavespeeds is much smaller, and serves to reduce them, marginally changing the ray geometry of SKS and SKKS at the CMB but not changing the form of the travel time curves. If the increased sulfur content raised wavespeeds above the shear wave speed at the base of the mantle, minor arc SKKS would re-emerge (see the SS97a model in Fig. 8), but this is not predicted by the core liquid model used (see the "Appendix" section). Panning et al's (2017) seismic wavespeed model brings mantle shear-wave speeds very close to core compressional wave speed, holding out the hope that the shallow core may be illuminated better by SKS and SKKS.

The Brunt-Väisälä frequency of the stratified layer is $\sim 0.4 \mathrm{mHz}(0.7 \mathrm{~h}$ period), suggesting strong stratification resistant to convection (Loper 2000). A simple calculation shows how difficult it would be to disrupt the stratification. The density change $\delta \rho / \rho$ due to a temperature change $\Delta T$ is $\alpha \Delta T$, whereas the density change due to a compositional gradient in the radial range $\Delta r$ is $\rho^{-1}(d \rho / d r) \Delta r$. Equating these and taking the radial derivative, The temperature gradient required to eradicate the density gradient is therefore $d T / d r=$ $(\alpha \rho)^{-1} d \rho / d r$. Using characteristic values $\alpha \approx 4.7 \times$ $10^{-5} \mathrm{~K}^{-1}, \rho \approx 6400 \mathrm{~kg} \mathrm{~m}^{-3}$ (Table 2), and $d \rho / d r \approx 0.875 \mathrm{~kg} \mathrm{~m}^{-3} \mathrm{~km}^{-1}$ (Fig. 6) a temperature gradient of $\sim 2.9 \mathrm{~K} \mathrm{~km}^{-1}$ is required. If the core's thermal conductivity is $30 \mathrm{~W} \mathrm{~m}^{-1} \mathrm{~K}^{-1}$, this would entail a core heat flux of $87 \mathrm{~mW} \mathrm{~m} \mathrm{~m}^{-2}$ or $0.88 \mathrm{TW}$, in the range of sublithospheric heat flux estimates of $15-40 \mathrm{~mW} \mathrm{~m}^{-2}(0.69-$ 1.84 TW) (Ruiz et al. 2011). Hence, the core heat flux required to disrupt layering entails the unlikely requirement of zero radiogenic heat production in Mars' mantle. It is also a higher core heat flux than encountered in any of the post-plate tectonic Mars mantle evolution scenarios explored by Nimmo and Stevenson (2000) and Williams and Nimmo (2004).

The clearest evidence for stratification is the presence of an inner core. Figure 5 shows that crystallization at the base of Mars' core occurs only at low temperatures below $\sim 1420 \mathrm{~K}$. At these temperatures, Fe would already be snowing from the $\mathrm{CMB}$ region, forming the stratified layer. Hence, if an inner core exists, the core must be stratified (with the proviso that $\mathrm{S}$ is the major alloying element and present in the concentration range of 11-17 wt\%). It is possible to stratify without an inner core if the CMB temperature is less than $\sim 1850 \mathrm{~K}$ at the lowest expected sulfur content, $11 \mathrm{wt} \%$, but this lies well below the limits found by geophysical modeling (Rivoldini et al. 2011). In the range 11-14 wt\% sulfur, an effectively pure iron inner core could form below a substantially stratified liquid in 

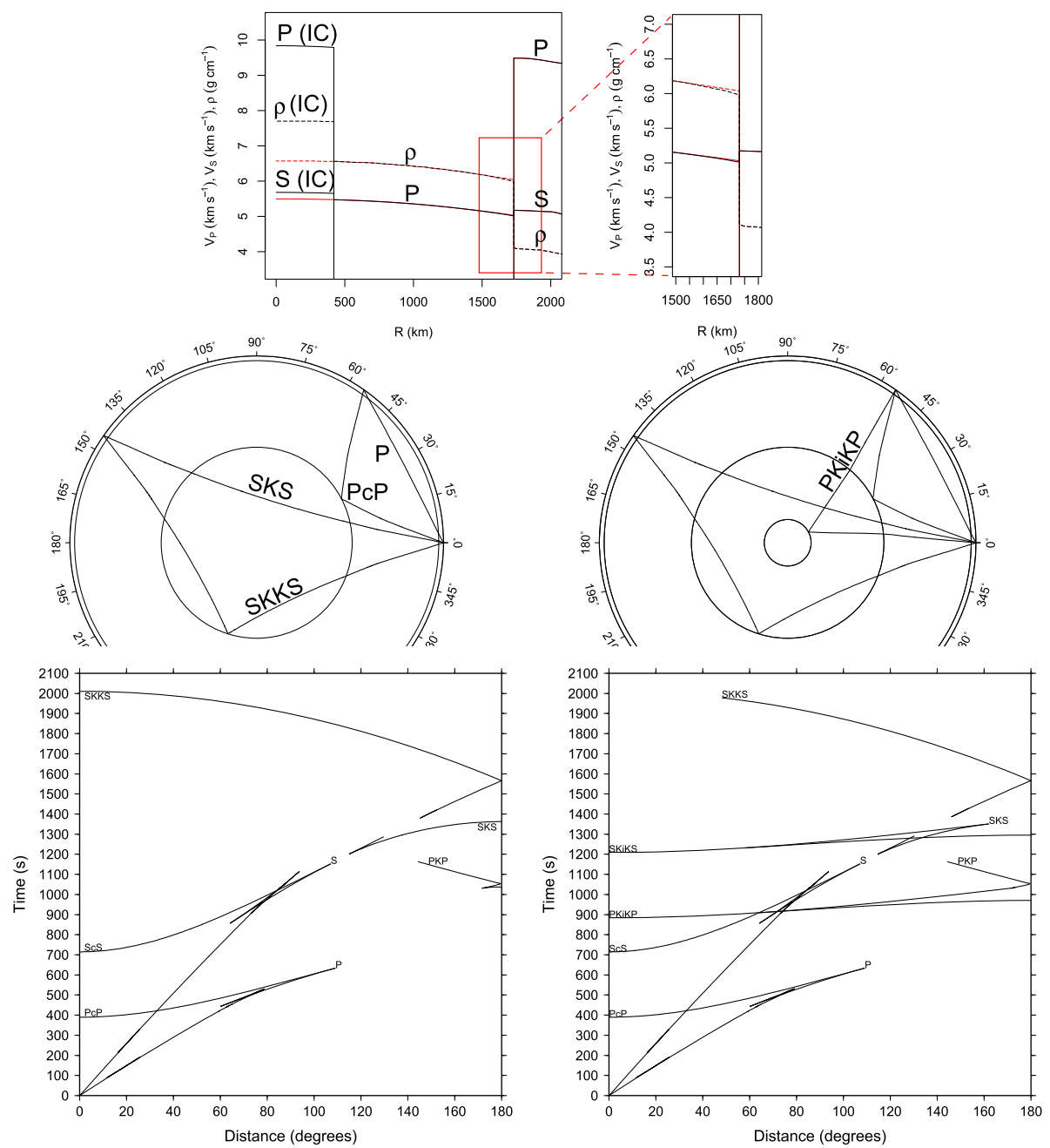

Fig. 10 Mars core structure when stratification and crystallization of an inner core occur simultaneously. Top panels show size of inner core (assumed $\mathrm{Fe}_{3} \mathrm{~S}_{2}$ ) and slight perturbation to density and P wave speed at the top of the outer core when stratification enriches sulfur in the core, lowering both density $\rho$ and $\mathrm{P}$ wave speed in the outer core relative to unstratified state (red lines). The profiles of P, S and $\rho$ in the inner core are labeled with (IC) for clarity; the unstratified P and $\rho$ profiles (red) continue smoothly to Mars' center. The inset (top right) of the boxed area near the CMB expands the density and $P$ wavespeed profiles to emphasize their subtle structural changes. Bottom panels show ray paths and travel times for unstratified (left) and stratified (right) cases. The stratification itself is unobservable because P wavespeeds are already lower than $\mathrm{S}$ in the mantle, blocking minor-arc SKKS (Fig. 8, top). The only visible consequence of stratification is the presence of the inner core itself, indicated by the existence of PKiKP (and its extension to $180^{\circ}$ as PKIKP)

the temperature range $1375-1575 \mathrm{~K}$ enriched in sulfur by up to $2.5 \mathrm{wt} \%$ over the bulk core content.

Between 1575-1850 K, there would be no inner core but a stratified outer core, whose stratification depth varies with temperature. Detecting the stratification could be difficult for the reason discussed above concerning the relative wavespeed of $\mathrm{S}$ at the base of the mantle to $\mathrm{P}$ in the liquid outer core.

Functioning dynamos in small planetary bodies appear to be a common outcome of the accretion process (Monteux et al. 2011). In Mars' case, dynamo activity ended early in the planet's history (Acuña et al. 1999).
Perhaps this was mediated by impacts as, for example, Monteux et al. (2015) envisage, but internal processes might also curtail dynamo activity. I explore this possibility in the following paragraph.

Temperatures at the $\mathrm{CMB}$ are expected to be in the range of $1700-2100 \mathrm{~K}$ based on the internal planetary models cited earlier. In this range, core stratification is possible if the bulk sulfur content is less than $13 \mathrm{wt} \%$. At the lowest temperature and lowest sulfur content (11 wt\%), about half of the core's depth would be stratified (Fig. 5), and any dynamo would have to operate within a radius of $\sim 1000 \mathrm{~km}$. The heat flux required to operate 
a thermal dynamo would also have to be carried conductively through a thick stagnant layer. One can use dynamo scaling relations developed by Christensen and Aubert (2006) to decide whether dynamo extinction through a change in conductive heat transport is possible. The relations are strictly valid for annular dynamos, so I assume a small inner core of $100 \mathrm{~km}$ radius and a well-mixed liquid region extending to $1100 \mathrm{~km}$ radius. This roughly corresponds to a scenario where the $T_{\mathrm{CMB}}$ is $1700 \mathrm{~K}$ and the bulk sulfur content is $11 \mathrm{wt} \%$; the top of the core will be enriched to $13 \mathrm{wt} \%$. Using the thermophysical values given in Table 2, I calculate the amount of heat flux in excess of the adiabat to drive a dynamo by heat alone at the critical Rayleigh number, $R a_{C}^{*}$. The details are relegated to the table for completeness; the result is simply that a heat flow excess $Q_{e}$ of at least $1.8 \%$ over the adiabatic flow in the convective region is required. This heat flow must be carried through the stagnant layer conductively, along an unknown temperature profile (either superadiabatic or subadiabatic depending on $T_{\mathrm{CMB}}$ compared with the temperature in the convective region). However, the liquid will be increasingly sulfur rich, changing the thermal conductivity and hence its capacity to transport heat from below. Using Gomi et al. (2013) model for thermal conductivity dependence on impurities in liquid iron, a $2 \mathrm{wt} \%$ increase in sulfur content will reduce $k$ by $2.2 \%$, which is slightly more than the excess heat $(1.8 \%)$ required to operate a critical dynamo. Thus, the growth of the sulfur-rich stratified layer acts to quell dynamo action in the core both by shrinking the dynamo region (increasing $R a_{Q, c}^{*}$ ), and by inhibiting its ability to cool itself (decreasing $Q_{a d v}$ ).

The calculation for the chosen parameters yield only a marginal suppression of dynamo activity and are uncertain. The main control over whether it arises in Mars is the core's bulk sulfur content: the higher it is, the less extensive stratification will be, but the more likely an inner core will be.

Stratification will be difficult to observe directly. However, Birch's homogeneity test (Birch 1952) of the core wavespeed profile, once it is determined, may yield a verdict on the core's chemical composition. Figure 11 shows a profile of the homogeneity index $\eta_{B}=d K / d P+g^{-1} d \Phi / d r$ (Dziewonski and Anderson 1981) for a synthetic Mars core wavepseed model based on Rivoldini et al. (2011) (see the "Appendix" section for methods used). $\eta_{B} \approx 1$ indicates adiabatic compression of a homogeneous substance. The homogeneity index is roughly 1 in the unstratified part of the core but changes substantially through the stratified region, even though the wavespeeds only change slightly, with no major changes in the shape of the travel time curves. If a good radial wavespeed model is available for the core, this test could reveal whether the core is stratified, and therefore unable to fully convect. This would be a strong constraint on Mars' evolution from the timing of the disappearance of its magnetic field.

Table 2 Mars thermophysical properties relevant for dynamo activity

\begin{tabular}{|c|c|c|c|c|}
\hline Symbol & Quantity & Value & Units and scale & Source \\
\hline$\Omega$ & Rotational frequency & 1.28126 & $\times 10^{-5} \mathrm{~s}^{-1}$ & (Turcotte and Schubert 2002) \\
\hline$R_{i}$ & Inner core radius & 100 & $\mathrm{~km}$ & \\
\hline$R_{0}$ & Outer radius of convective region & 1100 & $\mathrm{~km}$ & \\
\hline$D$ & Convective region thickness & & & $=R_{i}-R_{0}$ \\
\hline$g_{0}$ & Gravitational acceleration at top of convective region & 1.99 & $\mathrm{~ms}^{-2}$ & \\
\hline$\alpha$ & Thermal expansivity & 4.7 & $\times 10^{-5} K^{-1}$ & (Helffrich and Kaneshima 2004) for Fe-11wt\%S \\
\hline$T_{0}$ & Temperature at top of convective region & 1850 & K & Rivoldini et al. (2011) adiabat \\
\hline$T_{C M B}$ & CMB temperature & 1700 & K & (Rivoldini et al. 2011) \\
\hline$C_{p}$ & Heat capacity & 600 & $\mathrm{~J} \mathrm{~kg}^{-1} \mathrm{~K}^{-1}$ & (Helffrich and Kaneshima 2004) for Fe-11wt\%S \\
\hline$\rho$ & Density & 6390 & $\mathrm{~kg} \mathrm{~m}^{-3}$ & (Rivoldini et al. 2011) \\
\hline$v$ & Viscosity & 1 & $\times 10^{-6} \mathrm{~m}^{2} \mathrm{~s}^{-1}$ & (Christensen and Aubert 2006) \\
\hline$\kappa$ & Thermal diffusivity & 2 & $\times 10^{-5} \mathrm{~m}^{2} \mathrm{~s}^{-1}$ & (Christensen and Aubert 2006) \\
\hline k & thermal conductivity in convective region & 30 & $W m^{-1} K^{-1}$ & (Stacey 1992) \\
\hline E & Ekman number & 8.05 & $\times 10^{-14}$ & $=v\left(\Omega D^{2}\right)^{-1}$ \\
\hline$E_{k}$ & Thermal Ekman number & 1.61 & $\times 10^{-12}$ & $=\kappa\left(\Omega D^{2}\right)^{-1}$ \\
\hline \multirow[t]{2}{*}{$R a_{Q, c}^{*}$} & Modified critical Rayleigh number & 9.19 & $\times 10^{-9}$ & $=R a_{c} E E_{k}($ Christensen and Aubert 2006); \\
\hline & & & & $R a_{c}$ from Al-Shamali et al. (2004) \\
\hline
\end{tabular}

$R a_{Q, C}^{*}=\frac{1}{4 \pi R_{0} R_{i}} \frac{\alpha g_{0} Q_{a d v}}{\rho C p \Omega^{3} D^{2}} ; Q_{a d}=k \frac{\alpha g_{0} T}{C_{p}}$. Total heat flux $Q=Q_{a d v}+Q_{a d} ;$ heat flow excess to operate dynamo $Q_{e}=Q_{a d v} / Q$ 


\section{Conclusions}

This review summarized the knowledge of Mars' interior structure, its inferred composition, and its conjectured seismological properties arising from compositional possibilities. From the fairly detailed liquidus diagram summarizing the existing experimental studies, I discussed the set of processes that could act within Mars' core: an iron "snow" from the core-mantle boundary's surface and a $\mathrm{Fe}_{3-\mathrm{x}} \mathrm{S}_{2}$ "ground fog" forming at the base of the core. The temperature and compositional range at which these crystallization processes operate can imprint the core with identifiable structural features. From the seismic wavespeed and density profiles, I examined the key raypaths for the likely set of seismic wave arrivals and assessed their ability to diagnose chemical and thermal conditions in Mars' core.

In the near future, after InSight places a seismometer on Mars and records sufficient seismic activity on and within the planet, the resulting data will allow stronger inferences about its composition and evolution to be made. The most important datum to extract will be the radius of Mars' core that will be evident from PcP (and ScS) travel times. This will provide first-order constraints on the planetary $\mathrm{Fe} / \mathrm{Si}$ ratio. The next most important seismic observation will be the presence or absence of an inner core. If an inner core is detected, temperatures in Mars' core must be much lower than expected (1375-1420 K at the CMB).

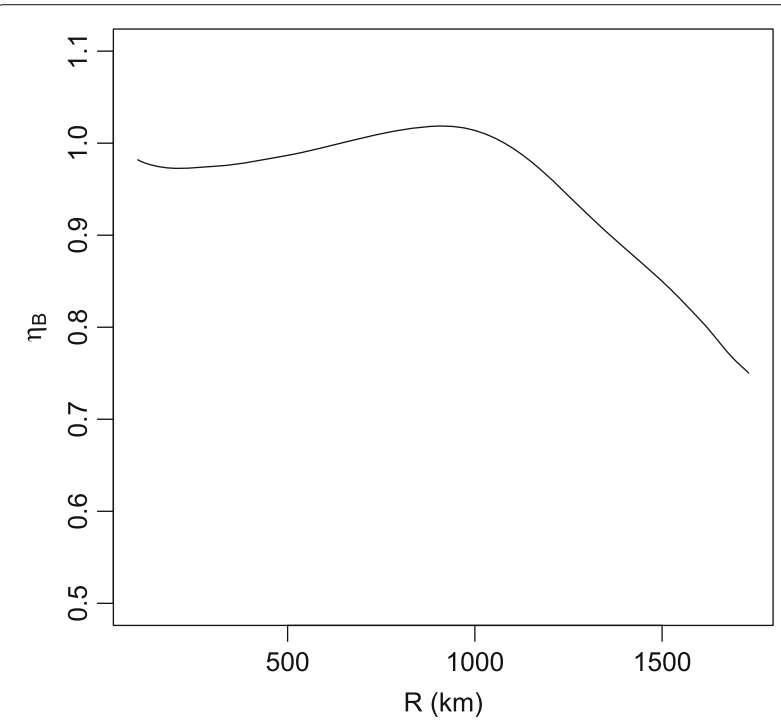

Fig. 11 Plot of homogeneity index for stratified core based on Rivoldini et al. (2011) model. The index $\eta_{B}$ is 1 for self-compression of a homogeneous substance. The bulk sulfur content is $11 \mathrm{wt} \%$, and $T_{C M B}=1700 \mathrm{~K}$. This causes the topmost $\sim 500 \mathrm{~km}$ of the core to be enriched in sulfur compared to the bulk. The index is approximately 1 in the innermost part of the outer core, but uniformly decreases in the topmost $500 \mathrm{~km}$ of the outer core where the sulfur concentration increase changes the wavespeed more strongly than the increase in pressure in a homogeneous material does
Wavespeeds in the core, particularly those derived from SKS and SKKS, should be able to constrain the extent of any stratification in the outer core, and, if present, restrict internal conditions to a combination of the bulk sulfur composition and CMB temperature. Finally, provided that sufficiently large seismic events can set the body of the planet oscillating, records of the long-period vibrational eigenfrequencies will yield independent constraints on the planet's density structure. Most planetary probes yield surprises, and there is no reason to expect Mars to fail to astonish.

\section{Appendix}

\section{Methods used}

Nomenclature for ray paths. A ray path is broken into segments, each described by a letter tabulated below. Each segment either starts at the earthquake focus or at one of the main seismic discontinuities in a planet: (1) the surface; (2) the core-mantle boundary (CMB); (3) the inner core-outer core boundary (ICB). Table 3 is a partial list that omits symbols not discussed in the review. See, for example, Shearer (2009) Chapter 4.9 for an extended discussion with more examples.

Starting from the focus, a wave leaves it as either a $\mathrm{P}$ or an $\mathrm{S}$ wave. As the wave meets one of the boundaries, it is either transmitted or reflected there and a new symbol describes the next segment in the path. Thus PKIKP is a P wave that crosses the outer core (K) to the inner core (I), where it reaches its maximum depth and turns upward to cross back into the core (K) and the mantle (P). Similarly, SKKS starts as $\mathrm{S}$ at the source, enters the core $(\mathrm{K})$, reflects off the bottom of the CMB (K) and leaves the core as an S wave that travels to the surface.

Seismic wave amplitudes. The amplitude of a seismic wave is governed by the intensity of the seismic source, the relative impedance of the material at the source and the receiver, geometric focusing (and defocusing) by shrinkage and expansion of wavefronts by the radial structure of the medium, and by reflections and conversions of seismic waves at major boundaries crossed by the wave front (such as the core-mantle boundary). All except the first and the last of these factors is expressed in the following rela-

Table 3 Symbols used to describe rays

\begin{tabular}{ll}
\hline Symbol & Use \\
\hline $\mathrm{P}$ & A downgoing $P$ wave in the mantle \\
$\mathrm{S}$ & A downgoing S wave in the mantle \\
$\mathrm{K}$ & A P wave in the outer core \\
$\mathrm{C}$ & A P wave in the inner core \\
$\mathrm{i}$ & A reflection from the CMB topside \\
\hline
\end{tabular}


tion (Shearer 2009):

$$
\frac{\hat{E}(\Delta)}{E_{s}}=\frac{p v_{s r c}^{2}}{4 \pi r_{s r c}^{2} r_{r e c}^{2} \sin \Delta \cos \theta_{s r c} \cos \theta_{r e c}}\left|\frac{d p}{d \Delta}\right| .
$$

The subscripts $s r c$ and $r e c$ designate quantities evaluated at the source and the receiver, respectively. $p$ is the spherical wave slowness, $v$ is the wave speed, $r$ is the radius, $\Delta$ is the angular separation between the source and receiver, and $\theta$ is the wavefront normal angle with respect to the radially downward direction. Specifically, $\frac{\hat{E}(\Delta)}{E_{s}}$ is the energy per unit of wavefront relative to the intensity of the source. The seismic wave amplitude is the square root of this quantity.

The effect of reflections and conversions at major boundaries (the core-mantle boundary in Mars' case) is accounted for by using the Zöppritz equations evaluated with appropriate material properties at the boundary and incoming and outgoing wavefront normal angles (Young and Braile 1976). These are combined with the geometric focusing and turned into a ratio of the amplitude of an arrival interacting with the core (PcP, SKKS, etc.) to the direct $\mathrm{P}$ or $\mathrm{S}$ wave arriving at the same distance.

The source intensity is obtained from Teanby and Wookey (2011) who calculated the seismic acceleration vs distance relation for an isotropic compressional energy source in Mars model at a range of source moments. I use the rule of thumb for crustal earthquakes on Earth (Hardebeck and Shearer 2003) to scale the P source intensity to an $\mathrm{S}$ source intensity; those authors found empirical agreement with the theoretical relation of the $\mathrm{S}$ intensity being 10 times the P intensity.

Again following Teanby and Wookey (2011), the detection threshold $a_{\text {peak }}$ is (Havskov and Alguacil 2004):

$$
a_{\text {peak }}=\frac{5}{4} n_{r m s}[\Delta f]^{1 / 2} \text {, }
$$

where $\Delta f$ is the noise bandwidth, chosen to be (4-0.4) Hz (Teanby and Wookey 2011). Given the reported SP and VBB instrument sensitivities $n_{r m s}$ of $10^{-8} \mathrm{~m} \mathrm{~s}^{-2} \mathrm{~Hz}^{-1 / 2}$ and $10^{-9} \mathrm{~m} \mathrm{~s}^{-2} \mathrm{~Hz}^{-1 / 2}$ (Lognonné et al. 2014), these provide the positions of the lines in Fig. 9. The source moment is converted to a moment magnitude using its defining relation (Hanks and Kanamori 1979).

Seismic wavespeeds in the inner core. Saxena and Ericsson (2015) estimated the thermophysical properties for $\mathrm{Fe}_{3} \mathrm{~S}_{2}$ and $\mathrm{Fe}_{3} \mathrm{~S}$ at a reference state of 1 bar and $1350 \mathrm{~K}$. I use those reference state values, listed in Table 4, to calculate the seismic wavespeed at core pressures and temperatures. A third order Birch-Murnaghan equation of state is used, as described in Helffrich and Connolly (2009), but with the finite strain-based thermal expansivity pressure dependence as used by Helffrich (2017). The solid equation of state gives both density $\rho$, isothermal bulk modulus $K$, and thermal expansivity $\alpha$ at high pressure and temperature. The seismic wavespeed is calculated from $V_{P}=\left[\left(K_{s}+4 / 3 \mu\right) / \rho\right]^{1 / 2}$, where the adiabatic bulk modulus $K_{s}=K(1+T \alpha \gamma)$. A Poisson solid is assumed in order to estimate the shear modulus $\mu$, yielding $\mu=K_{s} / 3$.

Velocity profiles in a stratified core. Liquid metal seismic wavespeeds in the Fe-S system are calculated using the model of Helffrich and Kaneshima (2004). Deviations of $V_{P}$ and $\rho$ from a homogenous sulfur concentration in the core are calculated down an adiabat footed at the CMB. The deviations $\delta V_{P}(r)$ and $\delta \rho(r)$ are expressed as multiplicative factors and applied to the $V_{P}$ and $\rho$ profiles from Rivoldini et al. (2011) to harmonize the different methods used to calculate wavespeeds in the two studies.

Core liquidus. To approximately model the core's liquidus we account for the melting depression due to the presence of a light element in the core. Because sulfur is cosmochemically abundant, lowers iron's freezing point, and is experimentally investigated, we use data for the Fe$\mathrm{FeS}$ eutectic to account for this effect on the formation of the inner core.

The calculated melting temperature of pure iron (Alfè et al. 2002), calibrated with shock melting results for iron (Nguyen and Holmes 2004) provide the melting temperature for pure iron. I parameterize the liquidus temperature as a function of composition for high iron concentrations using the Fe-FeS eutectic compositions and temperatures investigated as a function of pressure from various sources (Buono and Walker 2015; Chudinovskikh and Boehler 2007; Fei et al. 1997, 2000, Morard et al. 2008). The pressure and compositionally dependent melting temperature is parameterized as

$$
T(P, X)=T_{F e}(P)-c X^{2},
$$

where $T_{F e}$ is the iron melting curve and $c$ is a pressuredependent coefficient required to make $T(P, X)$ be the eutectic temperature $T_{e}(P)$ at the eutectic composition $X_{e}(P)$. The parabolic dependence is in contrast to Dumberry and Rivoldini 2015 who made a linear interpolation between the pure Fe melting point and the eutectic. For Mars's core, $P$ and $T$ is in the experimentally determined range (Chudinovskikh and Boehler 2007; Morard et al.

Table 4 Thermophysical properties

\begin{tabular}{lllll}
\hline \multirow{2}{*}{ Symbol } & Property & \multicolumn{2}{c}{ Value } & \multirow{2}{*}{ Scale and units } \\
\cline { 3 - 4 } & & $\mathrm{Fe}_{3} \mathrm{~S}_{2}$ & $\mathrm{Fe}_{3} \mathrm{~S}$ & \\
\hline$V_{0}$ & Molar volume & 32.848 & 27.370 & $\mathrm{cc} \mathrm{mol}^{-1}$ \\
$\alpha$ & $\begin{array}{l}\text { Thermal expansivity } \\
K_{0}\end{array}$ & 1 & 1 & $\times 10^{-5} \mathrm{~K}^{-1}$ \\
& $\begin{array}{l}\text { Isothermal bulk } \\
\text { modulus }\end{array}$ & 300 & 150 & $\mathrm{GPa}$ \\
$K^{\prime}$ & $\begin{array}{l}\text { Pressure derivative of } \\
\text { bulk modulus }\end{array}$ & 6 & 3.67 & \\
\hline
\end{tabular}

Reference state 1 bar and $1350 \mathrm{~K} . \gamma=1.4$ for all phases; $\delta_{T}=K^{\prime}$ for all phases too 
2008). I similarly parameterize the liquidus temperature of $\mathrm{Fe}_{(3-\mathrm{x})} \mathrm{S}_{2}$ from Fei et al. (1997, 2000), Stewart et al. (2007) and Morard et al. (2008) to determine the liquidus P-T$\mathrm{X}$ relations for $\mathrm{Fe}_{(3-\mathrm{x})} \mathrm{S}_{2}$. Stewart et al. (2007) showed $\mathrm{Ni}$ to have an insignificant effect on the melting relations, so its presence is neglected. Due to lack of compositional information, I assume the the incongruent melting $\mathrm{Fe}_{(3-\mathrm{x})} \mathrm{S}_{2}$ to $\mathrm{FeS}+$ liquid reaches an asymptotic composition of $26 \mathrm{wt} \% \mathrm{~S}$ along Morard et al. (2008) melting curve. In contrast, Dumberry and Rivoldini (2015) assumed that the eutectic composition decreased exponentially with pressure towards a value of $11 \mathrm{wt} \% \mathrm{~S}$ (compare Fig. 3), and did not parameterize the incongruent melting of $\mathrm{Fe}_{(3-\mathrm{x})} \mathrm{S}_{2}$ at all.

\section{Abbreviations}

CMB: Core-mantle boundary; ICB: Inner core boundary

\section{Acknowledgements \\ I thank James Dohm for discussions about Mars geology, and him and Shigenori Maruyama for the impetus to write about Mars' internal structure. Matthieu Laneuville and Nick Teanby gave some valuable suggestions to earlier drafts of the manuscript and provided some key preprints.}

\section{Funding}

Not applicable.

\section{Competing interests}

The author declares that he has no competing interest.

\section{Publisher's Note}

Springer Nature remains neutral with regard to jurisdictional claims in published maps and institutional affiliations.

Received: 10 February 2017 Accepted: 17 August 2017

Published online: 06 September 2017

\section{References}

Acuña MH, Connerney JEP, Ness NF, Lin RP, Mitchell D, Carlson CW, McFadden J Anderson KA, Rème H, Mazelle C, Vignes D, Wasiliewski P, Cloutier P (1999) Global distribution of crustal magnetization discovered by the Mars Global Surveyor MAG/ER experiment. Science 284:790-793

Al-Shamali FM, Heimpel MH, Aurnou JM (2004) Varying the spherical shell geometry in rotating thermal convection. Geophys Astrophys Fluid Dyn 98:153-169

Alfè D, Price GD, Gillan MJ (2002) Iron under Earth's core conditions: liquid state thermodynamics and high-pressure melting curve from ab-initio calculations. Phys Rev B 65:10-110365165118

Allègre CJ, Poirier J-P, Humler E, Hofmann AW (1995) The chemical composition of the Earth. Earth Planet Sci Lett 134:515-526

Anderson DL, Miller WF, Latham GV, Nakamura Y, Toksöz MN, Dainty AM, Duennebier FK, Lazarewicz AR, Kovach RL, Knight TCDD (1977) Seismology on Mars. J Geophys Res 82:4524-4546

Banerdt W, Smrekar S, Lognonné P, Spohn T, Asmar S, Banfield D, Boschi L, Christensen U, Dehant V, Folkner W, Giardini D, Goetze W, Golombek M, Grott M, Hudson T, Johnson C, Kargl G, Kobayashi N, Maki J, Mimoun D, Mocquet A, Morgan P, Panning M, Pike W, Tromp J, van Zoest T, Weber R, Wieczorek M, Garcia R, Hurst K (2013) InSight: a discovery mission to explore the interior of Mars. In: 44th Lunar and Planetary Science Conference. Lunar and Planetary Inst, Houston. p 1915

Birch F (1952) Elasticity and constitution of the earth's interior. J Geophys Res 57:227-286

Buono AS, Walker D (2015) $\mathrm{H}$, not O or pressure, causes eutectic T depression in the Fe-FeS System to 8 GPa. Meteor Planet Sci 50:547-554
Christensen U. R, Aubert J (2006) Scaling properties of convection-driven dynamos in rotating spherical shells and application to planetary magnetic fields. Geophys J Int 166:97-114

Chudinovskikh L, Boehler R (2007) Eutectic melting in the system Fe-S to 44 GPa. Earth Planet Sci Lett 257:97-103

Dreibus G, Palme H (1996) Cosmochemical constraints on the sulfur content in the Earth's core. Geochim Cosmochim Acta 60:1125-1130

Dreibus G, Wänke H (1985) Mars, a volatile-rich planet. Meteoritics 20:367-381

Dreibus G, Wänke H (1987) Volatiles on Earth and Mars: A comparison. Icarus $71: 225-240$

Dumberry M, Rivoldini A (2015) Mercury's inner core size and core-crystallization regime. Icarus 248:254-268

Dziewonski A, Anderson DL (1981) Preliminary reference Earth model. Phys Earth Planet Inter 25:297-356

Esposito PB, Banerdt WB, Lindal WL, Sjogren WL, Slade MA, Bills BG, Smith DE, Balmino G (1992) Gravity and topography. In: Kieffer HH, Jakosky BM, Snyder CW, Matthews MS (eds). Mars. U. Ariz. Press, Tucson. pp 209-248

Fei Y, Bertka CM, Finger LW (1997) High-pressure iron-sulfur compound, Fe3S2, and melting relations in the Fe-FeS system. Science 275:1621-1623

Fei Y, Li J, Bertka CM, Prewitt CT (2000) Structure type and bulk modulus of Fe3S, a new iron-sulfur compound. Am Mineral 85:1830-1833

Gomi H, Ohta K, Hirose K, Labrosse S, Caracas R, Verstraete MJ, Hernlund JW (2013) The high conductivity of iron and thermal evolution of the Earth's core. Phys Earth Planet Inter 224:88-103

Hanks TC, Kanamori H (1979) A moment magnitude scale. J Geophys Res $84: 2348-2350$

Hardebeck JL, Shearer PM (2003) Using S/P amplitude ratios to constrain the focal mechanisms of small earthquakes. Bull Seismol Soc Am 93:2434-2444

Havskov J, Alguacil G (2004) Instrumentation in Earthquake Seismology. Springer, Amsterdam

Helffrich G (2017) A finite strain approach to thermal expansivity's pressure dependence. Am Mineral. (in press)

Helffrich G, Connolly JAD (2009) Physical contradictions and remedies using simple polythermal equations of state. Am Mineral 94:1616-1619

Helffrich G, Kaneshima S (2004) Seismological constraints on core composition from Fe-O-S liquid immiscibility. Science 306:2239-2242

Kilburn MR, Wood BJ (1997) Metal-silicate partitioning and the incompatibility of S and Si during core formation. Earth Planet Sci Lett 152:139-148

Konopliv AS, Asmar SW, Folkner WM, Karatekin O, Nunes DC, Smrekar SE Yoder CF, Zuber MT (2011) Mars high resolution gravity fields from MRO, Mars seasonal gravity, and other dynamical parameters. Icarus 211:401-428

Konopliv AS, Yoder CF, Standish EM, Yuan D-N, Sjogren WL (2006) A global solution for the Mars static and seasonal gravity, Mars orientation, Phobos and Deimos masses, and Mars ephemeris. Icarus 182:23-50

Lodders K, Fegley B (1997) An oxygen isotope model for the composition of Mars. Icarus 126:373-394

Lognonné P, Banerdt W, Pike T, Giardini D, Christensen U, Banfield D, Mimoun D, Laudet P, de Raucourt S, Bierwirth M, Zweifel P, Calcutt S, Hurst K, Bruce C (2014) SEIS/INSIGHT and Mars seismology: Development status and focus on the Impact detection. Geophys Res Abst 14:12183

Loper DE (2000) A model of the dynamical structure of Earth's outer core. Phys Earth Planet Inter 117:179-196

Lorenz R. D, Nakamura Y (2013) Viking seismometer record: data restoration and dust devil search. In: 44th Lunar and Planetary Science Conference. Lunar and Planetary Institute, Houston. p 1178

Masters G, Gubbins D (2003) On the resolution of density within the Earth. Phys Earth Planet Inter 140:159-167

McDonough WF, Sun S-S (1995) The composition of the Earth. Chem Geol 120:223-253

Monteux J, Amit H, Choblet G, Langlais B, Tobie G (2015) Giant impacts, heterogeneous mantle heating and a past hemispheric dynamo on Mars. Phys Earth Planet Inter 240:114-124

Monteux J, Jellinek AM, Johnson CL (2011) Why might planets and moons have early dynamos? Earth Planet Sci Lett 310:349-359

Morard G, Andrault D, Guignot N, Sanloup C, Mezouar M, Petitgirard S, Fiquet G (2008) In situ determination of Fe-Fe3S phase diagram and liquid structural properties up to 65 GPa. Earth Planet Sci Lett 272:620-626

Nguyen J, Holmes NC (2004) Melting of iron at the physical conditions of the Earth's core. Nature 427:339-342

Nimmo F, Stevenson DJ (2000) Influence of early plate tectonics on the therma evolution and magnetic field of Mars. J Geophys Res 105(E5):11969-11979 
Olson P, Christensen UR (2002) The time-averaged magnetic field in numerical dynamos with non-uniform boundary heat flow. Geophys J Int 151:809-823

Panning MP, Beucler E, Drilleau M, Mocquet A, Lognonné P, Banerdt WB (2015) Verifying single-station seismic approaches using Earth-based data: Preparation for data return from the InSight mission to Mars. Icarus 248:230-242

Panning MP, Lognonné P, Banerdt WB, Garcia R, Golombek M, Kedar S, Knapmeyer-Endrun B, Mocquet A, Teanby NA, Tromp J, Weber R, Beucler E, Blanchette-Guertin J-F, Bozdag E, Drilleau M, Gudkova T, Hempel S, Khan A, Lekić V, Murdoch N, Plesa A-C, Rivoldini A, Schmerr N, Ruan Y, Verhoeven O, Gao C, Christensen U, Clinton J, Dehant V, Giardini D, Mimoun D, Pike WT, Smrekar S, Wieczorek M, Knapmeyer M, Wookey J (2017) Planned Products of the Mars Structure Service for the InSight Mission to Mars. Space Sci Rev:10-10071121401603175. (in press)

Rivoldini A, Hoolst T. V, Verhoeven O, Mocquet A, Dehant V (2011) Geodesy constraints on the interior structure and composition of Mars. Icarus 213:451-472

Rubie DC, Gessmann CK, Frost DJ (2004) Partitioning of oxygen during core formation on the Earth and Mars. Nature 429:58-61

Rückriemen T, Breuer D, Spohn T (2015) The Fe snow regime in Ganymede's core: a deep-seated dynamo below a stable snow zone. JGR-Planets 120:1095-1118

Ruiz J, McGovern PJ, Jiménez-Díaz A, López V, Williams J-P, Hahn BC, Tejero R (2011) The thermal evolution of Mars as constrained by paleo-heat flows. Icarus 216:508-517

Saxena S, Eriksson G (2015) Thermodynamics of Fe-S at ultra-high pressure. CALPHAD 51:202-205

Seidelmann PK, Abalakin VK, Bursa M, Davies ME, de Bergh C, Lieske JH, Oberst J, Simon JL, Standish EM, Stooke P, Thomas PC (2002) Report of the IAU/IAG working group on cartographic coordinates and rotational elements of the planets and satellites: 2000. Celest Mech Dynam Astron 82:83-110

Shearer PM (2009) Introduction to seismology. Cambridge University Press, Cambridge

Sohl F, Spohn T (1997) The interior structure of Mars: implications from SNC meteorites. J Geophys Res 102:1613-1635

Stacey FD (1992) Physics of the Earth. Brookfield Press, Kenmore

Stewart AJ, Schmidt MW, van Westrenen W, Liebske C (2007) Mars: a new core-crystallization regime. Science 316:1323-1325

Takahashi F, Matsushima M (2006) Dipolar and non-dipolar dynamos in a thin shell geometry with implications for the magnetic field of Mercury. Geophys Res Lett 33:10-10292006025792

Taylor J, Teanby N, Wookey J (2013) Estimates of seismic activity in the Cerberus Fossae region of Mars. J Geophys Res-Planets 118:2570-2581

Teanby N, Wookey J (2011) Seismic detection of meteorite impacts on Mars. Phys Earth Planet Inter 186:70-80

Turcotte DL, Schubert G (2002) Geodynamics. Cambridge University Press, Cambridge

Wänke H, Dreibus G (1988) Chemical composition and accretion history of terrestrial planets. Philos Trans R Soc London Ser A 325:545-557

Weiss BP, Vali H, Baudenbacher FJ, Kirschvink JL, Stewart ST, Shuster DL (2002) Records of an ancient Martian magnetic field in ALH84001. Earth Planet Sci Lett 201:449-463

Williams J-P, Nimmo F (2004) Thermal evolution of the Martian core: Implications for an early dynamo. Geology 23:97-100

Wood BJ, Walter MJ, Wade J (2006) Accretion of the Earth and segregation of its core. Nature 441:825-833

Yoder CF, Konopliv AS, Yuan DN, Standish EM, Folkner WM (2003) Fluid core size of Mars from detection of the solar tide. Science 300:299-303

Young GB, Braile LW (1976) Application of Zoeppritz's amplitude and Knott's energy equations. Bull Seismol Soc Am 66:1881-1886

\section{Submit your manuscript to a SpringerOpen ${ }^{\circ}$ journal and benefit from:}

- Convenient online submission

- Rigorous peer review

- Open access: articles freely available online

- High visibility within the field

- Retaining the copyright to your article

Submit your next manuscript at $>$ springeropen.com 